\title{
A Sex-Limited Serum Protein Variant in the Mouse: Inheritance and Association with the $\boldsymbol{H}$-2 Region
}

\author{
Howard C. Passmore ${ }^{1}$ and Donald C. Shreffler ${ }^{1}$
}

Received 7 Nov. 1969-Final 19 Dec. 1969

An alloantiserum produced in the mouse has been used to detect an antigen which is present only in male serum from certain inbred strains of mice, e.g., $D B A / 2 J, A / J$, and $B A L B / c$. Genetic tests reveal that the presence of this antigen is controlled by a dominant autosomal gene which is expressed only in males of the proper genotype. Test crosses and analysis of congenic resistant strains indicate close linkage between the sex-limited protein (Slp) and the histocompatibility-2 (H-2) region of linkage group IX. Analysis of seven intra-H-2 recombinant strains is consistent with the placement of the genetic determinant for Slp within the $\mathrm{H}-2$ region in the same position as the Ss (serum substance) determinant. Immunological evidence suggests that the Slp antigenic sites reflect structural variation in the Ss component of mouse serum.

\section{INTRODUCTION}

A quantitative serum protein variant associated with the histocompatibility-2 $(\mathrm{H}-2)$ locus has been described in the house mouse (Shreffler and Owen, 1963; Shreffler, 1964). The quantity of the variant protein (called the Ss protein) in the serum is controlled by two alleles, which determine large differences in Ss protein levels. These alleles have been designated $S s^{l}$ for low quantitative levels and $S s^{h}$ for high levels of this protein. The $S s^{h} / S s^{h}$ genotype (Ss-H phenotype) has approximately twenty times the level of serum Ss protein as the $S s^{l} / S s^{l}$ genotype (Ss-L phenotype). The heterozygote, $S s^{h} / S s^{l}$ (Ss-HL phenotype), has an intermediate level. Recombination mapping revealed that this locus is located within the complex $H$-2 region of linkage group IX, with the determinants of $\mathrm{H}-2$ antigenic specificities lying both to the right and to the left of the Ss determinant (Shreffler, 1965, 1967).

\footnotetext{
Supported by U.S.P.H.S. Research Grant GM-15419, U.S.P.H.S. Career Development Award K3-HE-24, 980 (D.C.S.), and U.S.P.H.S. Training Grant 2T01-GM-00071 (H.C.P.).

1 Department of Human Genetics, University of Michigan, Ann Arbor, Michigan.

(C) 1970 Plenum Publishing Corporation, New York, N.Y.
} 
In an effort to determine whether this locus controlling quantitative Ss expression is the structural locus for the Ss protein or merely has a regulatory effect on an Ss structural gene located elsewhere in the genome, a search was begun for structural differences in the Ss protein. For this purpose, partially purified preparations of Ss protein were used for cross-alloimmunizations between different inbred strains of mice.

This report describes a qualitative serum protein variant which was revealed by alloimmunization and which is characterized by autosomal dominant genetic control, sex-limitation, genetic association with the $H$-2 region, and molecular association with the Ss protein. This variant has been tentatively designated the sex-limited protein (Slp) and the controlling locus designated Slp. A preliminary report of these findings has been published (Passmore and Shreffler, 1968).

\section{METHODS}

Inbred strains of mice were obtained either from our own colony or from The Jackson Laboratory, Bar Harbor, Maine, with the exception of YBR/a, obtained from Dr. Morris Foster of the University of Michigan. The congenic resistant and $H-2$ recombinant lines were from our own stocks. The strains studied are listed in Table IV.

The inheritance of the Slp trait was examined in crosses between strains C57BL/6J and DBA/2J and between C57BL/6J and A/J. (C57BL/6J $\left.9 \times \mathrm{DBA} / 2 \mathrm{~J}_{\sigma}\right) \mathrm{F}_{1}$ hybrids (hereafter shortened to $\mathrm{B} 6 \mathrm{D} 2)$ and $\left(\mathrm{C} 57 \mathrm{BL} / 6 \mathrm{~J}\right.$ 우 $\left.\times \mathrm{A} / \mathrm{J}^{\star}\right) \mathrm{F}_{1}$ hybrids (shortened to $\mathrm{B} 6 \mathrm{~A}$ ) were purchased from The Jackson Laboratory, while the reciprocal $F_{1}$ hybrids (D2B6 and AB6) as well as reciprocal backcross and $F_{2}$ generations were produced in this laboratory.

Ss protein was partially purified for immunizations by applying $5.0-6.0 \mathrm{ml}$ of DBA/2J or A/J whole serum to a 1.5 by $90 \mathrm{~cm}$ Sephadex G-200 column and eluting with phosphate-buffered saline, $p \mathrm{H} \mathrm{7.0.} \mathrm{The} \mathrm{Ss-positive} \mathrm{fractions} \mathrm{were} \mathrm{pooled} \mathrm{and}$ concentrated two to three times original concentration. In some later immunizations, antigen was prepared using Slp-positive fractions. In one case, Ss protein precipitated with anti-Ss was used for immunization.

Alloimmunizations for the production of anti-Slp were made by subcutaneous injections of $0.2 \mathrm{ml}$ of the partially purified Ss preparation emulsified in an equal volume of complete Freund's adjuvant at days $0,14,21$, and 28 followed by an intraperitoneal injection at day 42 without adjuvant. Animals were bled 7 days after the last injection and every second day thereafter for approximately 1 week. Pools of $\mathrm{RF} / \mathrm{J}_{\widehat{\sigma}}$ anti-A/J $\mathrm{J}$ or $\mathrm{RF} / \mathrm{J}_{\widehat{\sigma}}$ anti-DBA/2J $\widehat{\text { ô }}$ were used for routine Slp typing.

Antiserum for Ss typing was prepared according to Shreffler and Owen (1963).

Blood for serum typing was drawn from the retro-orbital sinus and allowed to clot. The serum was then drawn off and typed immediately, with the excess being stored at $-80 \mathrm{C}$. Animals were tested only after 10 weeks of age since the Slp antigen does not begin to appear in the serum until approximately 6-8 weeks of age. Individual animals were typed at least twice using separate bleedings. In any case of discrepancy (usually animals that were classified as negative on the first typing and positive on the second, because they were late in developing the Slp antigen), repeat typings were done with separate bleedings. 
Serum Slp typing was done by microslide immunodiffusion using a modification of the method of Ridgway et al. (1962), in which the antibody and antigen wells are $4 \mathrm{~mm}$ in diameter and spaced $7 \mathrm{~mm}$ apart (center to center). The immunodiffusion slides were read for the Slp reaction at $18 \mathrm{~h}$. The method of Ss typing was the microslide technique previously described by Shreffler (1964). Quantitation of the Ss protein was performed by double immunodiffusion in tubes according to the method of Preer (1956) as modified by Shreffler (unpublished).

Agar immunoelectrophoresis was carried out on 8 by $10 \mathrm{~cm}$ glass plates using a $1 \%$ concentration of No. 2 Ionagar (Colab Laboratories) in a $p \mathrm{H} 8.6$ veronal-calcium lactate buffer, modified from Hirschfeld (1959) by a $25 \%$ reduction in molarity of the buffer components. The cell buffer was the same as that used by Hirschfeld (1959). Electrophoresis was run for $90 \mathrm{~min}$ at $5.0 \mathrm{v} / \mathrm{cm}$ on an Immunobox immunoelectrophoresis cell (Model EC640, E-C Apparatus Corp.).

$\mathrm{H}-2$ typing was carried out using the polyvinylpyrrolidine (PVP) method essentially as described by Stimpfling (1961), with minor modifications (Shreffler et al., 1966). The basic method was modified by the addition of $0.3 \%$ bovine serum albumin, as used by Snell (personal communication). Typing sera for specificity $\mathrm{H}-2.4$ were prepared as previously described (Shreffler et al., 1966), using the following strain combinations: $(\mathrm{C} 3 \mathrm{H} / \mathrm{JSf} \times \mathrm{STOLI} / \mathrm{Lw}) \mathrm{F}_{1}$ anti-DBA/2J and $(\mathrm{C} 57 \mathrm{BL} / 10 \mathrm{JSf} \times \mathrm{AKR} . \mathrm{M})$ $\mathrm{F}_{1}$ anti-A/Sn.

\section{RESULTS}

The immunization of $\mathrm{RF} / \mathrm{J}$ male mice with a partially purified preparation of $\mathrm{Ss}$ protein from DBA/2J male serum produced an antiserum which gave a well-defined precipitin line when tested on microslide immunodiffusion against sera from males of strains DBA/2JSf and A/J. However, the alloantiserum gave no reaction with sera from females of these same strains, and no reaction with the sera of animals of either sex from $\mathrm{C} 57 \mathrm{BL} / 6 \mathrm{~J}, \mathrm{C} 3 \mathrm{H} / \mathrm{JSf}$, and RF/J. The immunodiffusion plate in Fig. 1 illustrates the reaction of $\mathrm{RF} / \mathrm{J} \delta$ anti-DBA $/ 2 \mathrm{~J}$ oै serum with sera from strains $\mathrm{DBA} / 2 \mathrm{JSf}, \mathrm{A} / \mathrm{J}$, and

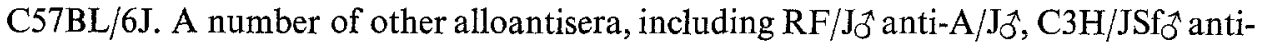

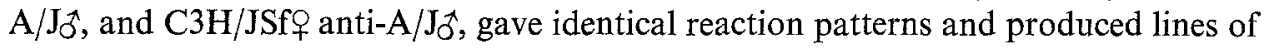

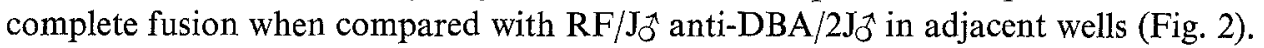
Since no reaction was observed with sera from females of any of the strains tested, a positive reaction with sera from males of a given strain was the criterion for designating the strain as positive for the reactive antigen, which will hereafter be referred to as the Slp (sex-limited protein) antigen. The reactive or positive phenotype will be designated Slp-a, the nonreactive or negative phenotype Slp-o.

Crosses were made between strains DBA/2J (Slp-a) and C57BL/6J (Slp-o) and $\mathrm{F}_{1}, \mathrm{~F}_{2}$, and backcross generations were produced to determine the inheritance of this serum antigen. The segregation of the Slp trait in the progeny of these crosses is shown in Table I. $F_{1}$ hybrid males from reciprocal crosses are all Slp-positive. This result rules out simple $\mathrm{X}$ - or $\mathrm{Y}$-linkage, and suggests dominant, autosomal inheritance. This is confirmed in the backcross and $F_{2}$ generations. All male progeny from the backcross to $\mathrm{DBA} / 2 \mathrm{~J}$ are positive, regardless of the direction of the cross. Among male progeny 


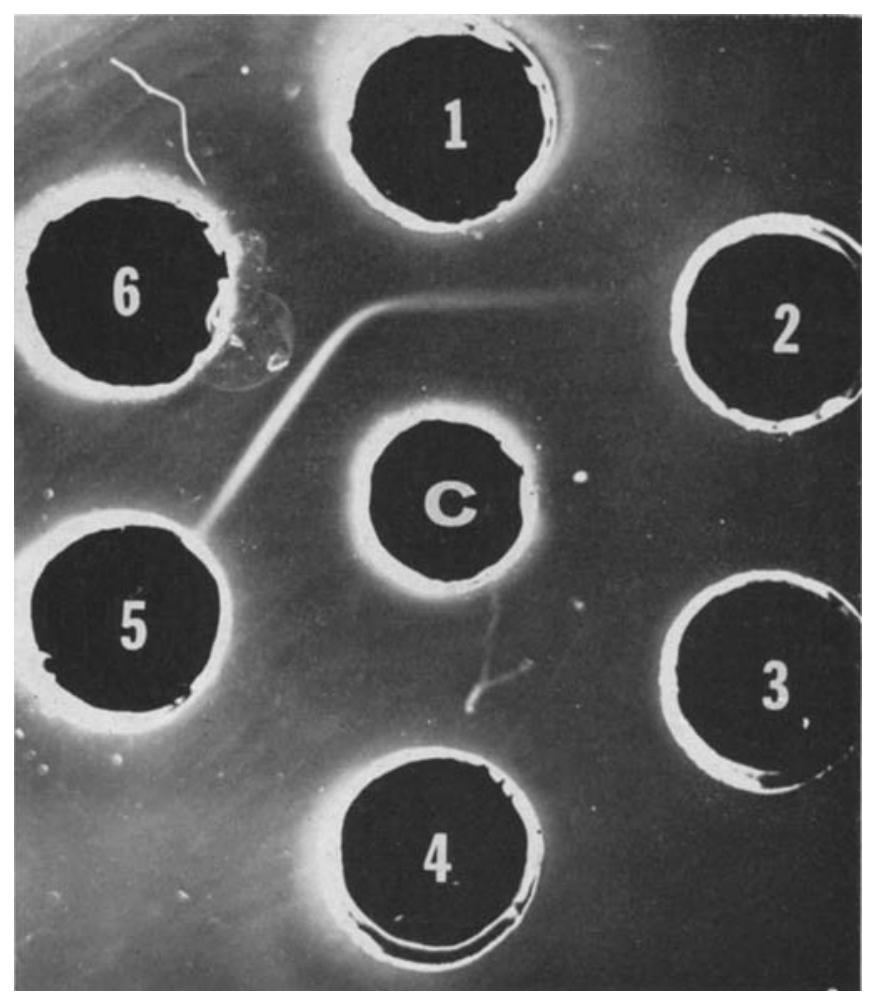

Fig. 1. Immunodiffusion plate illustrating the typing of inbred mouse sera for Slp. Anti-Slp (RF ${ }^{\star}$ anti-DBA/2J 3 ) is in the center well. Well 1: A/J ô serum. Well 2: A/J ㅇ serum. Well 3: C57BL/6Jô serum. Well 4: C57BL/6J o serum. Well 5: DBA/2J ㅇ serum. Well 6: DBA/ $2 \mathrm{~J}^{\widehat{ }}$ s serum. Undiluted adult sera were used in all wells.

from the backcrosses to the negative parent, the observed ratio of Slp-a to Slp-o is close to the expected $1: 1$ ratio, and the $F_{2}$ shows a close approximation to a $3: 1$ ratio. Note that, as in both parental strains, all females in these crosses are Slp-o, yet both $\mathrm{DBA} / 2 \mathrm{~J}$ and $\mathrm{F}_{1}$ females produce Slp-a male offspring when mated to Slp-o C57BL/6J males. This indicates that these females carry the gene for Slp-positivity, but do not express the antigen. The trait is therefore sex-limited, i.e., confined to expression in males, but controlled by a single, dominant, autosomal gene. The allele which determines presence of the antigen in males is designated $S l p^{a}$, the allele determining absence of the antigen is denoted $S l p^{\circ}$. Similar crosses between C57BL/6J and A/J (Table II) also support these conclusions.

Since the initial purpose of the alloimmunization was a search for structural variation in the $H$-2-linked Ss protein, the progeny from the backcrosses to C57BL/6J (Tables I and II) were classified for H-2 type, to test for linkage of Slp with $H-2$. Specificity $\mathrm{H}-2.4$ was utilized as the marker specificity for the $\mathrm{H}-2 \mathrm{~d}$ type derived from strain DBA/2J and the $\mathrm{H}-2 \mathrm{a}$ type of strain $\mathrm{A}$. Table III lists the four equally probable 


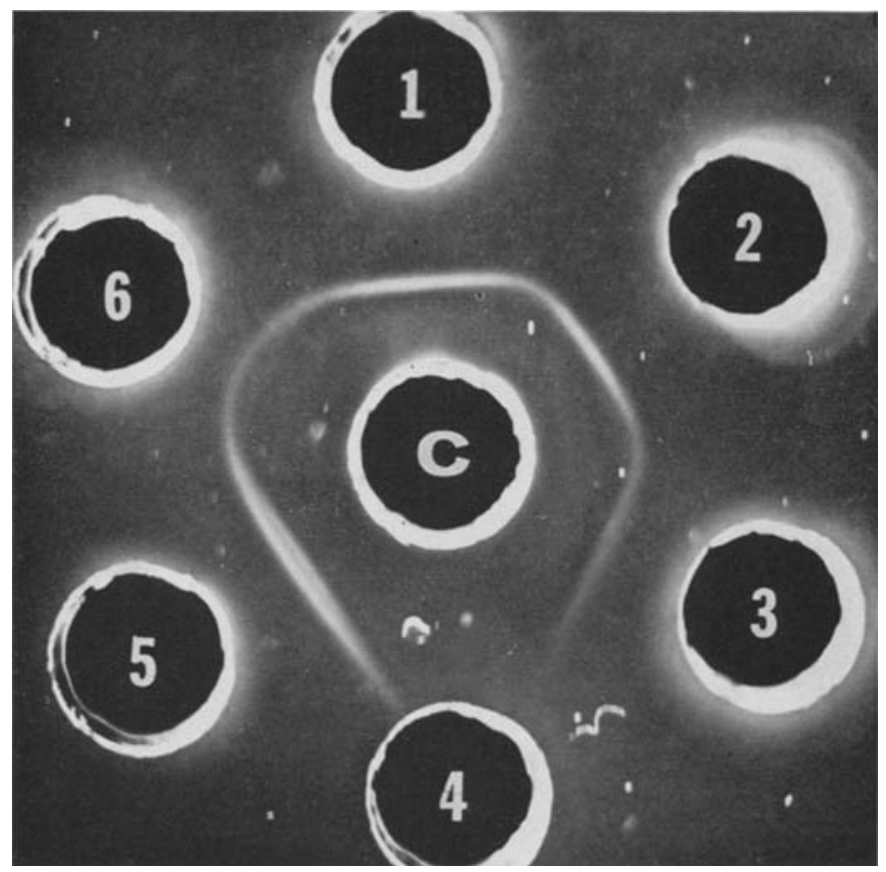

Fig. 2. Immunodiffusion reactions of various antisera prepared against partially purified Ss preparations. DBA $/ 2 \mathrm{~J}$ serum is in the

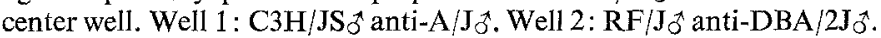
Well 3: $\mathbf{C} 3 \mathrm{H} / \mathbf{J S f}$ ㅇ anti-A/J $\mathbf{J}^{\star}$. Well 4: blank. Well 5: RF/J ${ }^{\star}$ antiDBA/2J $\delta$. Well 6: RF/J $\hat{\text { on }}$ anti-A/J $\delta$. Occasionally, splitting of the SIp band occurs as seen in the reaction with well 5 . The splitting is not regularly reproducible, and it is not known whether its occurrence is due to heterogeneity of the antigen or to artifact.

classes of male animals expected from these backcrosses under the hypothesis of independent assortment. As can be seen, however, only the two parental types (with respect to $\mathrm{H}-2.4$ and Slp) are maintained in the progeny of the test crosses, with only one apparent exception in 104 animals. These data, therefore, are indicative of very close linkage between $H-2$ and $S l p$. The one exception above ( 3486$)$ and an additional single exception ( 3300$)$ among the 128 animals tested in the $(\mathrm{C} 57 \mathrm{BL} / 6 \mathrm{~J} \times \mathrm{DBA} / 2 \mathrm{~J}) \mathrm{F}_{2}$ generation were both typed as $\mathrm{H}-2.4$ negative and Slp-a. Repeated hemagglutination tests and in vivo absorption tests confirmed that these animals were $\mathrm{H}-2.4$ negative. These two animals were progeny-tested by crossing each to C57BL/10J females. In both cases, H-2.4-negative Slp-a male offspring confirmed the exceptional type assigned to these animals. It seems reasonable to suspect that each of these animals resulted from an intra- $H-2$ crossover which carries the D end from the $H-2^{b}$ chromosome and the $\mathrm{K}$ end from $H-2^{d}$. Tests of additional $\mathrm{H}-2$ specificities are now being done to determine whether this is in fact the case.

The association of $S l p$ with $H-2$ can also be seen in a very striking way in the 
Table I. Slp Types of Progeny from the Cross C57BL/6J $\times$ DBA $/ 2$

\begin{tabular}{|c|c|c|c|c|c|c|}
\hline & $S l p-a$ & $S l p-o$ & $S / p-a$ & $S l p-o$ & $\begin{array}{c}\chi^{2} \\
\text { males }\end{array}$ & $\underset{\text { males }}{p}$ \\
\hline Parental generation & & & & & & \\
\hline $\mathrm{DBA} / 2$ & 18 & 0 & 0 & 10 & & \\
\hline C57BL/6J & 0 & 9 & 0 & 5 & & \\
\hline \multicolumn{7}{|l|}{$F_{1}$ generation $^{b}$} \\
\hline B6D2 & 6 & 0 & 0 & 5 & & \\
\hline D2B 6 & 11 & 0 & 0 & 6 & & \\
\hline Total & 17 & 0 & 0 & 11 & & \\
\hline \multicolumn{7}{|l|}{ Backcross to DBA/2 } \\
\hline $\mathrm{B} 6 \mathrm{D} 2 \times \mathrm{DBA} / 2$ & 31 & 0 & 0 & 12 & & \\
\hline $\mathrm{DBA} / 2 \times \mathrm{B} 6 \mathrm{D} 2$ & 17 & 0 & 0 & 13 & & \\
\hline Total & 48 & 0 & 0 & 25 & & \\
\hline \multicolumn{7}{|c|}{ Backeross to C57BL/6J } \\
\hline $\mathrm{B} 6 \mathrm{D} 2 \times \mathrm{C} 57 \mathrm{BL} / 6 \mathrm{~J}$ & 22 & 19 & 0 & 19 & 0.22 & $0.6-0.7$ \\
\hline $\mathrm{C} 57 \mathrm{BL} / 6 \mathrm{~J} \times \mathrm{B} 6 \mathrm{D} 2$ & 5 & 6 & 0 & 3 & & \\
\hline $\mathrm{C} 57 \mathrm{BL} 6 \mathrm{~J} \times \mathrm{D} 2 \mathrm{~B} 6$ & 7 & 8 & 0 & 12 & & \\
\hline Total & 34 & 33 & 0 & 34 & 0.02 & 0.9 \\
\hline \multicolumn{7}{|l|}{$\mathrm{F}_{2}$ generation } \\
\hline B6D2 $\times$ B6D2 & 39 & 12 & 0 & 30 & 0.06 & 0.8 \\
\hline $\mathrm{D} 2 \mathrm{~B} 6 \times \mathrm{D} 2 \mathrm{~B} 6$ & 55 & 22 & 0 & 18 & 0.35 & $0.5-0.6$ \\
\hline Total & 94 & 34 & 0 & 48 & 0.17 & $0.6-0.7$ \\
\hline
\end{tabular}

an each cross, only a sample of the total female progeny produced was tested, so the totals for females deviate from the totals for males.

${ }^{b} \mathrm{~B} 6 \mathrm{D} 2=$ shortened form for $\left(\mathrm{C} 57 \mathrm{BL} / 6 \mathrm{~J}\right.$ 우 $\left.\times \mathrm{DBA} / 2{ }^{\dagger}\right) \mathrm{F}_{1} . \mathrm{D} 2 \mathrm{~B} 6=$ shortened form for $\left(\mathrm{DBA} / 29 \times \mathrm{C} 57 \mathrm{BL} / 6 \mathrm{~J} \mathrm{O}^{\star}\right) \mathrm{F}_{1}$.

distribution of Slp and H-2 types in inbred strains. Table IV gives the Slp types of 38 inbred strains of mice (including congenic resistant strains) grouped according to $\mathrm{H}-2$ type to emphasize the association between $S l p$ and $H-2$. All males were tested with both

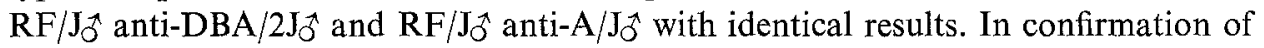
earlier suspicions of sex-limitation, females of all 38 strains are negative.

Table II. SIp Types of Progeny from the Cross C57BL $/ 6 \mathbf{J} \times \mathrm{A} / \mathrm{J}$ (Reciprocal Crosses Pooled)

\begin{tabular}{|c|c|c|c|c|c|c|}
\hline & \multicolumn{2}{|c|}{ Males } & \multicolumn{2}{|c|}{ Females $^{a}$} & \multirow{2}{*}{$\begin{array}{c}\chi^{2} \\
\text { males }\end{array}$} & \multirow{2}{*}{$\underset{\text { males }}{p}$} \\
\hline & $S l p-a$ & $S l p-o$ & $S l p-a$ & $S l p-o$ & & \\
\hline $\mathrm{A} / \mathrm{J}$ & 7 & 0 & 0 & 4. & & \\
\hline C57BL/6J & 0 & 9 & 0 & 5 & & \\
\hline $\mathrm{F}_{1}$ generation & 12 & 0 & 0 & 8 & & \\
\hline Backcross to $\mathrm{A} / \mathrm{J}$ & 20 & 0 & 0 & 10 & & \\
\hline Backcross to $\mathrm{C} 57 \mathrm{BL} / 6 \mathrm{~J}$ & 21 & 16 & 0 & 10 & 0.66 & 0.4 \\
\hline $\mathrm{F}_{2}$ generation & 37 & 17 & 0 & 22 & 1.21 & $0.2-0.3$ \\
\hline
\end{tabular}

${ }^{a}$ In each cross, only a sample of females was tested, so female totals deviate from male totals. 
Table III. Test Crosses for Determination of Linkage Between the $H$-2 Locus (Specificity 4) and Slp Type (Only Males Included)

\begin{tabular}{|c|c|c|}
\hline Phenotype & $\begin{array}{c}\text { Cross: } \\
(\mathrm{C} 57 \mathrm{BL} / 6 \mathrm{~J} \times \mathrm{DBA} / 2) \mathrm{F}_{1} \\
\times \mathrm{C} 57 \mathrm{BL} / 6\end{array}$ & $\begin{array}{c}\text { Cross: } \\
(\mathrm{C} 57 \mathrm{BL} / 6 \mathrm{~J} \times \mathrm{A} / \mathrm{J}) \mathrm{F}_{1} \\
\times \mathrm{C} 57 \mathrm{BL} / 6\end{array}$ \\
\hline$+4, \quad$ Slp-a & 33 & 16 \\
\hline$-4, \quad$ Slp-o & 33 & 21 \\
\hline$+4, \quad$ Slp-o & 0 & 0 \\
\hline$-4, \quad$ Slp-a & 1 & 0 \\
\hline
\end{tabular}

Notice that all $\mathrm{H}-2 \mathrm{a}$ and $\mathrm{H}-2 \mathrm{~d}$ strains are Slp-a, while all $\mathrm{H}-2 \mathrm{~b}$ and $\mathrm{H}-2 \mathrm{k}$ strains are Slp-o. This close relationship is even more apparent when the congenic resistant strains are considered. Congenic resistant strains are strains which are essentially identical genetically, except for the introduction of a different allele at a histocompatibility locus, in this case the $H-2$ locus. These strains have been produced by backcrossing different $H-2$ alleles onto certain inbred backgrounds for at least 10 generations.

Table IV. Distribution of Slp Type in Inbred Lines of Mice Arranged to Reflect the Association with H-2 Type

\begin{tabular}{|c|c|c|c|c|c|c|c|}
\hline Line & $\begin{array}{c}\text { Slp } \\
\text { males }\end{array}$ & $\begin{array}{c}\text { Slp } \\
\text { females }\end{array}$ & $\begin{array}{l}\mathrm{H}-2 \\
\text { type }\end{array}$ & Line & $\underset{\text { males }}{\text { Slp }}$ & $\begin{array}{c}\text { Slp } \\
\text { females }\end{array}$ & $\begin{array}{l}\mathrm{H}-2 \\
\text { type }\end{array}$ \\
\hline $\mathrm{A} / \mathrm{HeJ}$ & + & - & $\mathrm{a}$ & $\mathrm{P} / \mathrm{JSf}$ & + & - & $\mathrm{p}$ \\
\hline $\mathrm{A} / \mathrm{J}$ & + & - & $\mathrm{a}$ & $\mathrm{BDP} / \mathrm{J}$ & + & - & $\mathrm{p}$ \\
\hline $\mathrm{A} / \mathrm{SnSf}$ & + & - & $\mathrm{a}$ & & & & \\
\hline \multirow[t]{2}{*}{ B10.A/SnSf } & + & - & $\mathrm{a}$ & $\mathrm{DBA} / 1 \mathrm{JSf}$ & - & - & $\mathrm{q}$ \\
\hline & - & - & b & $\mathrm{C} 3 \mathrm{H} . \mathrm{Q} / \mathrm{Sf}$ & - & - & q \\
\hline C57BL $/ 6 \mathrm{~J}$ & - & - & $\mathrm{b}$ & C3H.RIII/Sf & - & - & $r$ \\
\hline $\mathrm{C} 57 \mathrm{~L} / \mathrm{J}$ & - & - & $\mathrm{b}$ & $\mathrm{CR} / \mathrm{Sf} \mathrm{f}^{a}$ & - & - & $\mathrm{r}$ \\
\hline A.BY/SnSf & - & - & b & & & & \\
\hline \multirow[t]{2}{*}{$129 / \mathrm{J}$} & - & - & b & D1.C/SnSf & + & - & c \\
\hline & & & & A.CA $/ \mathrm{SnSf}$ & - & - & f \\
\hline $\mathrm{DBA} / 2 \mathrm{JSf}$ & + & - & d & $\mathrm{CJ} / \mathrm{Sf}^{b}$ & + & - & $\mathrm{j}$ \\
\hline BALB/cAnM & + & - & $\mathrm{d}$ & I/AoSf & + & - & $\ddot{l}$ \\
\hline YBR/a & + & - & d & AKR.M/SnSf & - & - & $\mathrm{m}$ \\
\hline \multirow[t]{2}{*}{$\mathrm{B} 10 . \mathrm{D} 2 / \mathrm{SnSf}$} & + & - & d & $\mathrm{BF} / \mathrm{Sf} c^{c}$ & + & - & $\mathrm{n}$ \\
\hline & & & & A.SW/SnSf & + & - & s \\
\hline $\mathrm{AKR} / \mathrm{J}$ & - & - & k & $\mathrm{PL} / \mathrm{JSf}$ & + & - & $\mathrm{v}$ \\
\hline $\mathrm{CBA} / \mathrm{J}$ & - & - & $\mathrm{k}$ & WB/ReSf & - & - & $\mathrm{w}$ \\
\hline $\mathrm{C} 3 \mathrm{H} / \mathrm{JSf}$ & - & - & k & $\mathrm{FL} / 2 \mathrm{ReSf}$ & - & - & $?$ \\
\hline B10.K/Sf & - & - & $\mathrm{k}$ & $\mathrm{B} 10 . \mathrm{Y} / \mathrm{SnSf}$ & - & - & pa \\
\hline C57BR/cdJ & - & - & $\mathrm{k}$ & & & & \\
\hline C58/J & - & - & $\mathrm{k}$ & & & & \\
\hline $\mathrm{MA} / \mathrm{J}$ & - & - & $\mathrm{k}$ & & & & \\
\hline $\mathrm{RF} / \mathrm{J}$ & - & - & $\mathrm{k}$ & & & & \\
\hline
\end{tabular}

a Stock derived from C3H/JSf $\times$ RIII/Wy cross, inbred 18 generations.

${ }^{b}$ Stock derived from $\mathrm{C} 3 \mathrm{H} / \mathrm{JSf} \times \mathrm{JK} / \mathrm{St}$ cross, inbred 13 generations.

- Stock derived from C57BL/10JSf $\times$ F/St cross, inbred 14 generations. 


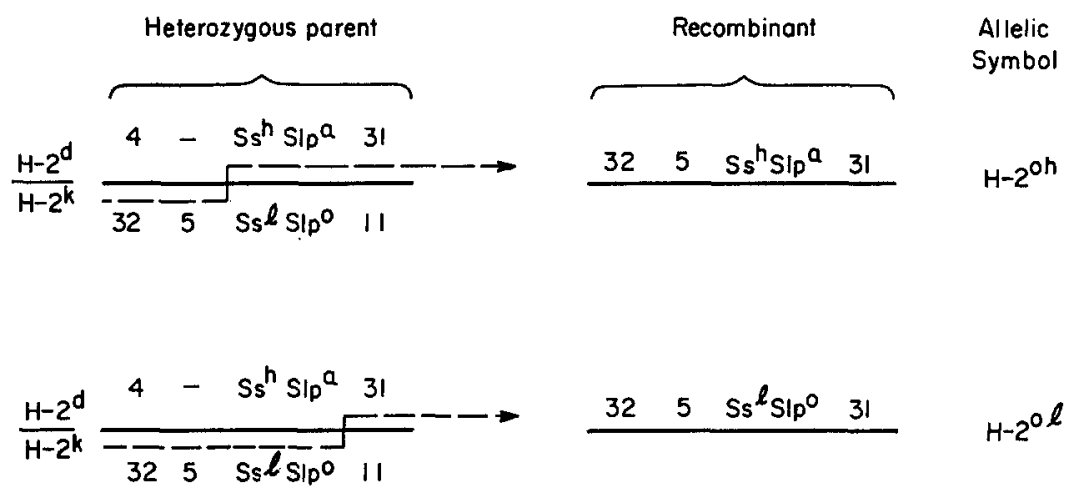

Fig. 3. A pair of intra-H-2 crossovers which position the $S l p$ determined within the $H-2$ region (see text for description). Only selected specificities have been included.

For example, C57BL/10 (synonym B10) and C57BL/10- $H-2^{a}$ (synonym B10.A) are congenic strains that are different only at the $H-2$ locus; their genetic background is the same. Notice that strain B10.A has a Slp type corresponding to the strain of origin of its H-2 type (strain A), not the Slp type of the background strain (C57BL/10). This relationship would be expected if $H-2$ and $S l p$ are closely linked. Four additional congenic resistant strains are informative in the same way: $\mathrm{A} / \mathrm{Sn}-\mathrm{H}-2^{b}$ (synonym A.BY), DBA/1JSn- $H-2^{c}$ (D1.C), C57BL/10ScSn- $H-2^{d}$ new (B10.D2), A/Sn- $H-2^{f}$ (A.CA).

The map position of $S l p$ in relation to $H-2$ was more precisely determined by analysis of a number of available strains derived from crossovers within the $H$-2 region. In Fig. 3, a pair of intra- $H-2$ recombinant chromosomes are diagrammed, designated $H-2^{o h}$ and $H-2^{o l}$ (see Shreffler, 1965; Shreffler et al., 1966; David and Shreffler, unpublished). On the left side of the table is the parental heterozygote combination in which the crossovers took place. Both crossovers were between alleles $H-2^{d}$ and $H-2^{k}$. At the right of the table are the configurations of the two recombinant chromosomes. Only selected $H-2$ specificities are included. In both cases, the recombinant chromosome contains specificities 32 and 5 from one chromosome and specificity 31 from the other parental chromosome, indicating that a crossover has occurred between the locations controlling these specificities. The recombinant chromosomes, as shown, have the same $H-2$ specificities but differ with respect to Ss type. Therefore, assuming that both represent single crossover events, in one case the crossover occurred to the left of the Ss segment and in the other case to the right of this segment. When males of these crossover types were tested for Slp type, the first was found to be Slp-a while the other was Slp-o. Since these two recombinants differ only with respect to a small chromosome segment within the $H$-2 region, the Slp determinant must also reside within the $H-2$ region. Analyses of five additional crossovers indicated a position for $S l p$ to the right of the intra- $H-2$ crossover point in four of them, while one indicates a position to the left of the intra- $H-2$ crossover point. All of these are consistent with a localization of $S l p$ within the $H-2$ region. 

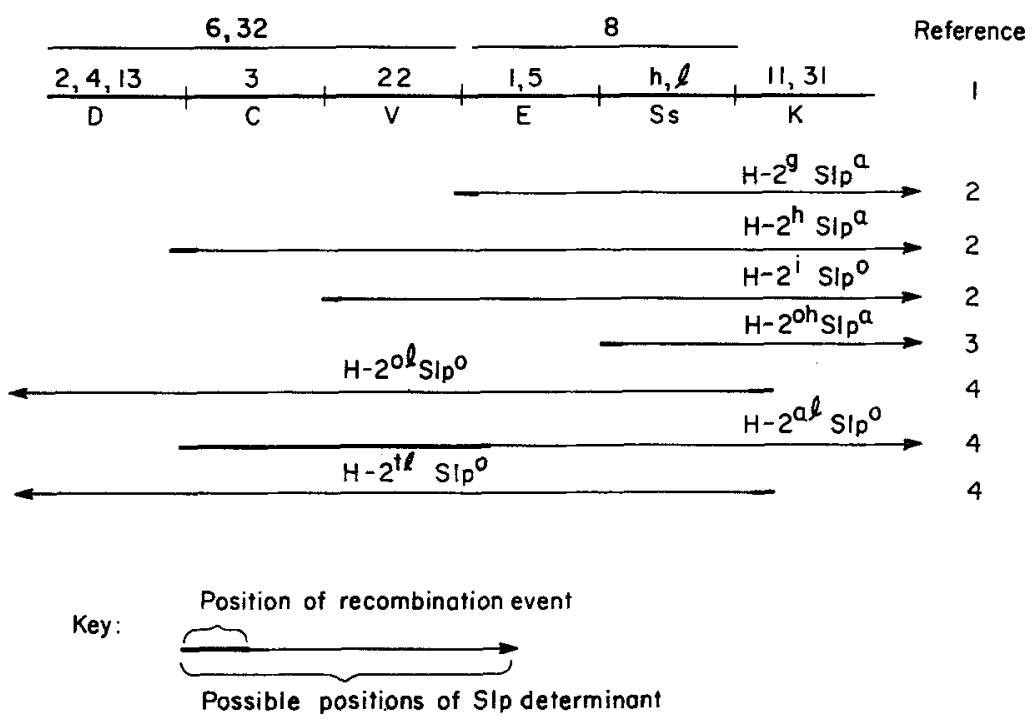

Fig. 4. Recombination map of the $H-2$ region of the mouse. Below the map are diagrammed the seven intra $-H-2$ recombinants which position the $S l p$ determinant within the $\mathrm{H}$-2 region (see text for description). Only selected $\mathrm{H}-2$ specificities are included in the map. References: 1. Shreffler (1967). 2. Gorer and Mikulska (1959). 3. Shreffler et al. (1966). 4. David and Shreffler (unpublished).

At the top of Fig. 4 is shown the recombination map of the $H-2$ region using selected specificities (from Shreffler, 1967). The bottom portion of Fig. 4 depicts the possible positions of $S l p$ with reference to the $H-2$ map, as determined by each of the seven informative recombinants. The possible crossover position for each of these recombinants was determined in the same manner as the two illustrated in Fig. 3. $\mathrm{H}-2$ specificities of each of these recombinants, as well as the parental heterozygote configurations, can be found in the references listed at the side of the figure. Slp types are given in the figure. It is apparent that the only possible position for $S l p$ that is common to all recombinants is the $S s$ segment within the $H-2$ region. Thus the genetic evidence is not inconsistent with the hypothesis that the Slp trait reflects variation in the Ss protein.

A number of experiments were carried out to determine whether the Slp variation was physically and chemically associated with the quantitatively controlled Ss protein. For this purpose, the immunological relationship between the Ss and Slp antigens was investigated. In Fig. 5 an agar immunodiffusion pattern is presented in which the antigen (normal mouse serum from strain DBA/2) was in one well, with anti-Slp and anti-Ss placed in adjacent wells. A spur is visible at the point of the junction of the two reaction lines with anti-Slp and anti-Ss. Such a reaction would be expected to occur with a heterogeneous antigen, in which some molecules contain Ss sites and Slp sites, while some molecules contain only Ss sites.

This apparent cross-reactivity between Ss and Slp antigens was confirmed in absorption studies designed to determine the effect of anti-Ss on Slp activity and con- 


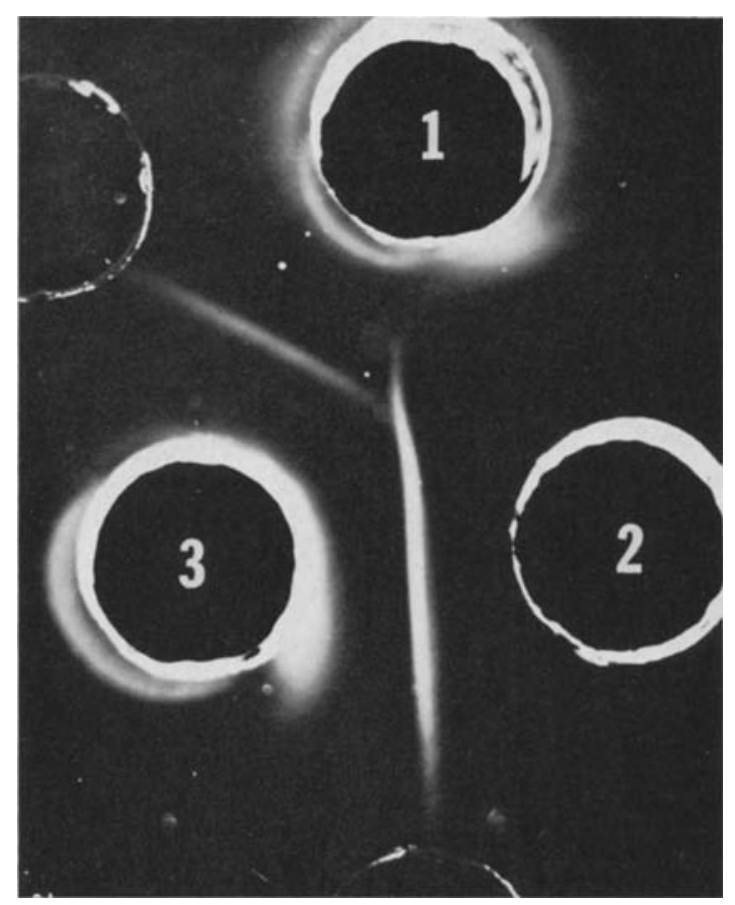

Fig. 5. Immunodiffusion plate showing the precipitin reactions of anti-Slp (well 1) and anti-Ss (well 2) with DBA $/ 2 J_{\circlearrowleft}$ serum (well 3 ).

versely the effect of anti-Slp on Ss activity. Unlike conventional absorption tests (in which antiserum is absorbed with antigen and then tested against a second antigen), antibody of one type was used to absorb antigen which was then tested for its ability to react with antibody of the other type. In the first series, DBA/2J male serum was absorbed with rabbit anti-Ss in tubes for $1 \mathrm{hr}$ at $37 \mathrm{C}$ and then 8 additional hrs at $4 \mathrm{C}$. The tubes were then centrifuged and the supernatant was tested for Slp reactivity

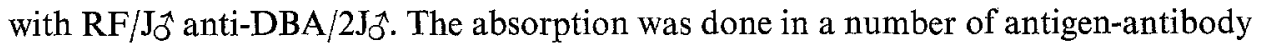
ratios from $2: 1$ to $1: 32$. As controls which should have no effect (other than dilution) on Slp reactivity, normal rabbit serum or phosphate-buffered saline was similarly mixed with DBA/2J male serum.

As can be seen in Table V, DBA/2J male serum can be diluted 1 part serum to 16 parts normal rabbit serum or phosphate-buffered saline and still give a positive reaction (lines 1 and 2, Table V). However, when 1 part DBA/J2 male serum is mixed with 2 parts anti-Ss, all Slp activity is removed (line 3 ). Note that the Slp activity is completely absorbed out at the same level of anti-Ss as that at which all Ss activity is lost (line 4). It appears, therefore, that anti-Ss is reactive with all molecules carrying the Slp antigenic determinant and is effective in absorbing out all Slp activity. This result is consistent with the hypothesis that all molecules carrying Slp sites also carry Ss sites. 
Table V. The Effect of Anti-Ss on Slp Reactivity

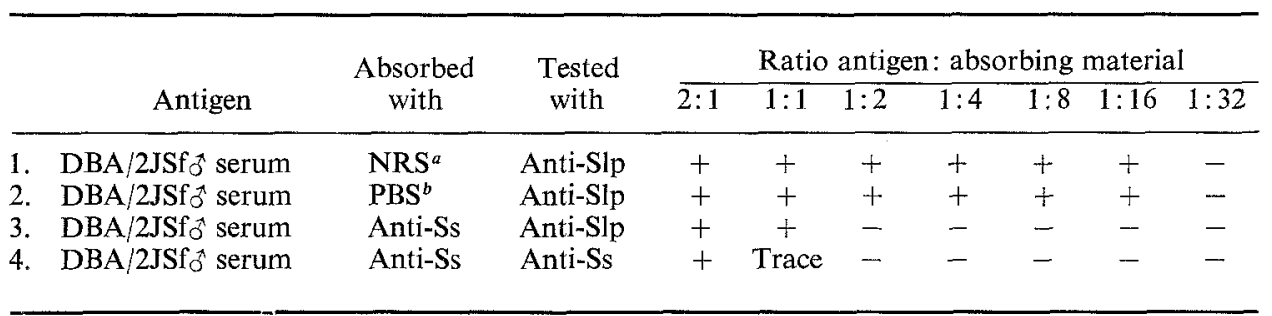

${ }^{a} \mathrm{NRS}=$ normal rabbit serum.

${ }^{b} \mathrm{PBS}=$ phosphate-buffered saline.

In the second series, DBA/2J male serum was absorbed with anti-Slp (RF/J $\mathrm{J}_{0}$ anti-DBA/2J for $1 \mathrm{hr}$ at $37 \mathrm{C}$, then overnight at $4 \mathrm{C}$. It was then centrifuged and tested for Ss reactivity with anti-Ss. In this case, the Ss activity was tested quantitatively in immunodiffusion tubes. Quantitation was necessary because the serum containing the anti-Slp (from strain RF/J) also contains Ss protein. This Ss protein will, of course, be SIp-negative. Fortunately, $\mathrm{RF} / \mathrm{J}$ is Ss-L and has only approximately one twentieth as much Ss protein as does DBA/2J, which is Ss-H. However, since a small amount of this Slp-negative Ss protein is present in each of the reaction tubes, all would be scored positive in a qualitative test. In the quantitative immunodiffusion tube method, the percentage reduction in antigen activity could be more reliably estimated.

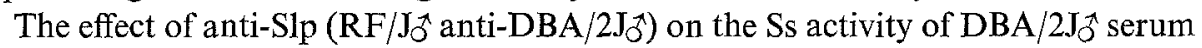
is shown in Table VI. In line $1, \mathrm{DBA} / 2 \hat{\sigma}$ serum was diluted with phosphate-buffered saline. These dilutions produced a linear calibration curve when precipitin line position was plotted against the $\log _{2}$ of the dilution. Units of Ss activity were assigned to each dilution based on 100 units $=$ undiluted DBA $/ 2 \mathrm{~J}_{\sigma}^{\star}$ serum. When DBA $/ 2 \mathrm{~J} \delta$ serum is absorbed with anti-Slp (line 4 ) at a ratio of 2 parts antigen to 1 part anti-Slp, Ss activity is reduced from 67 units to 25 units. Since the addition of anti-Slp adds a small amount of presumably non-reactive Ss in the form of Ss-L mouse serum, it is necessary to subtract this activity (estimated in line 5) from 25 units of activity to get a net

Table VI. The Effect of Anti-Slp on Ss Reactivity ${ }^{a}$

\begin{tabular}{|c|c|c|c|c|c|c|c|c|c|}
\hline & \multirow[b]{2}{*}{ Antigen } & \multirow{2}{*}{$\begin{array}{l}\text { Absorbed } \\
\text { with }\end{array}$} & \multirow{2}{*}{$\begin{array}{l}\text { Tested } \\
\text { with }\end{array}$} & \multicolumn{6}{|c|}{ Ratio antigen : absorbing material } \\
\hline & & & & $2: 1$ & $1: 1$ & $1: 2$ & $1: 4$ & $1: 8$ & $1: 16$ \\
\hline 1. & DBA/2JSf $\delta$ serum & PBS $^{b}$ & Anti-ss & 67 & 50 & 33 & 20 & 11 & No reaction \\
\hline 2. & $\mathrm{DBA} / 2 \mathrm{JSf} \not \hat{~ s e r u m}$ & Ss-L NMS ${ }^{c}$ & Anti-Ss & 69 & 57 & 37 & 21 & $\mathrm{NT}^{d}$ & NT \\
\hline 3. & DBA/2JSf serum & Anti-Slp & Anti-SIp & + & Trace & - & - & - & - \\
\hline 4. & DBA/2JSfo serum & Anti-SIp & Anti-Ss & 25 & $<11,>6$ & $<11$ & $<11$ & $<11$ & \\
\hline 5. & \multicolumn{3}{|c|}{$\begin{array}{l}\text { Calculated units of nonreactive } S_{s} \text { from } \\
\text { RF/J(Ss-L) antiserum }\end{array}$} & 2 & 3 & 3 & 4 & 5 & \\
\hline 6. & \multicolumn{3}{|c|}{$\begin{array}{l}\text { Net units of possibly reactive Ss protein } \\
\text { (line } 4 \text {-line 5) }\end{array}$} & 23 & $<8,>3$ & $<8$ & $<7$ & $<6$ & \\
\hline 7. & \multicolumn{3}{|c|}{ Loss of activity } & $66 \%$ & $84-94 \%$ & $76-100 \%$ & $65-100 \%$ & $46-100 \%$ & \\
\hline
\end{tabular}

${ }^{a}$ Reactions expressed in units of activity with undiluted DBA $/ 2 \mathrm{JSf}$ male serum $=100$ units,

${ }^{\circ} \mathrm{PBS}=$ phosphate.

c NMS $=$ normal mouse serum.

¿NT $=$ not tested. 


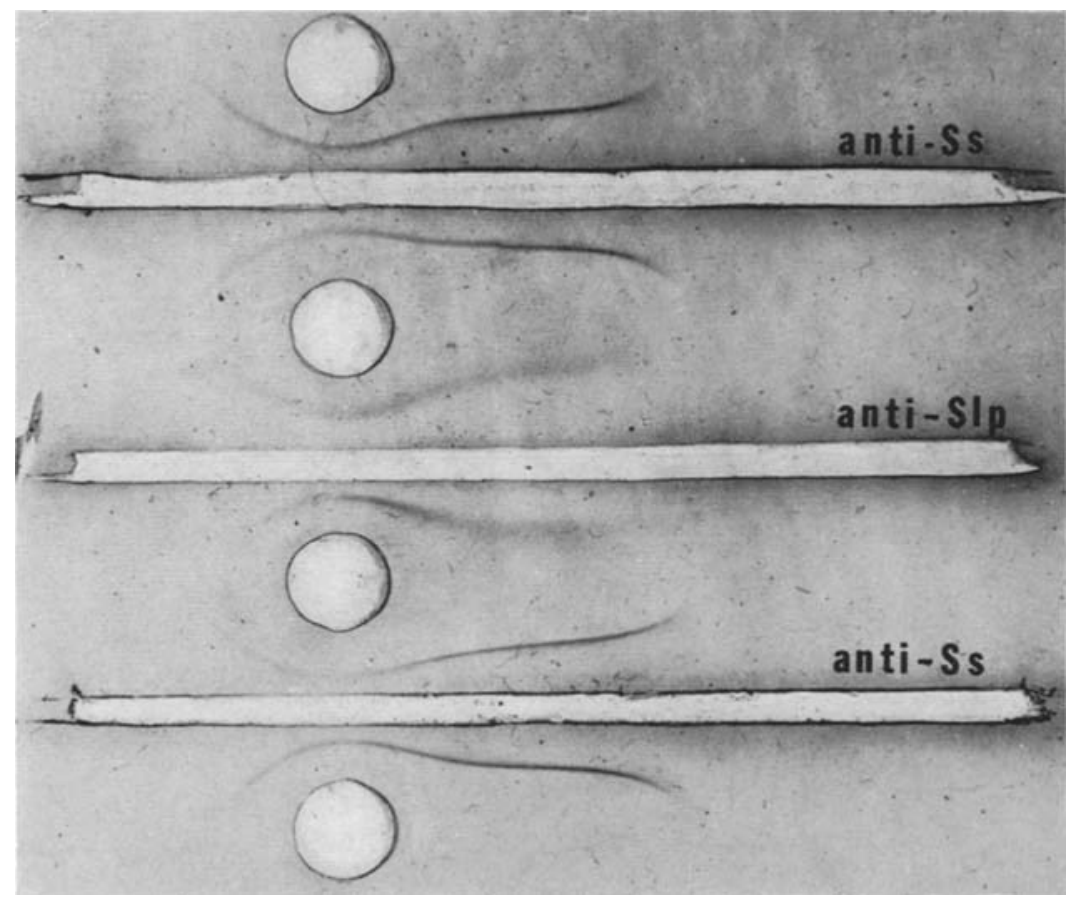

Fig. 6. Immunoelectrophoretic plate showing the precipitin reactions of anti-Ss and anti-Slp (RF ${ }^{\star}$ anti-DBA/2J ${ }^{-}$) with DBA/2J male serum. The anode was at the right.

remaining activity of 23 units (line 6). Ss activity at this absorption ratio was therefore reduced approximately $66 \%$ (line 7 ). In a similar way, percent loss of Ss activity can be calculated at each absorption ratio. The figure $<11$ is based on the last dilution standard (line 1) which will give a reaction on this immunodiffusion tube method (1:8 dilution or 11 units) and indicates the maximum score that can be assigned to a negative reaction. At the $1: 1$ ratio, absorption is almost complete, as indicated by the trace reaction with anti-Slp (line 3). At this ratio, approximately $84-94 \%$ of the Ss reactivity is lost. This seems to be the best minimum estimate that can be derived from this table since the calculations made from the three higher dilutions are increasingly less sensitive because of their increasing dilution.

In any case, substantial reduction of Ss level by anti-Slp can be demonstrated in this absorption series. It is not possible to determine whether this cross-reactivity is complete because of technical peculiarities of the absorption method; however, it seems that a substantial fraction, if not all, of the Ss protein molecules in Slp-a serum carry Slp antigenic sites.

On immunoelectrophoresis, Ss protein and the sex-limited protein give very similar migration patterns (Fig. 6), with the only difference being that a portion of the band formed by the Ss protein extends slightly more in the direction of the anode.

A number of experiments were conducted to determine the existence (if any) and 
the nature of the gene product of the $S l p^{o}$ allele. A rabbit antiserum was made against a Slp preparation, and no specific rabbit anti-Slp was found when the antiserum was absorbed with Slp-o serum. (A good anti-Ss was produced.) This would be expected if the $S l p^{o}$ allele produced a very similar gene product indistinguishable by the rabbit antiserum or if the rabbit failed to respond to the Slp specificity. A/J male animals were injected with Ss protein preparations from $\mathrm{C} 57 \mathrm{BL} / 6 \mathrm{~J}$ males in an attempt to demonstrate an allotypic specificity which would define the negative allele. Three such animals produced no antisera defining the $S l p^{\circ}$ allele. Further immunizations, using the following strain combinations, were also unsuccessful: B10.A $\hat{\jmath}$ anti-B10 $\hat{\jmath}$ (two animals) and DBA $2{ }^{\dagger}$ anti-B10 ${ }^{\star}$ (two animals using Ss anti-Ss precipitated complexes). With only negative results thus far, very little can be said from these approaches as to whether or not the $S l p^{\circ}$ allele produces an immunologically distinguishable product.

Development of the sex-limited protein occurs after sexual maturity in positive males. Eight DBA/2J males were tested for the antigen weekly from 3 to 10 weeks of age. All the animals were negative when tested at 3, 4, 5, and 6 weeks. Three animals were positive at 7 weeks and all were positive at 8 weeks, although the antigen did not reach full strength in some until 10 weeks of age. Eight DBA/2J females tested at the same intervals were always negative.

In addition to the serum, the Slp antigen is also present in ascites fluid of $\mathrm{A} / \mathrm{He}$ males. Seminal fluid, testes homogenate, and urine from DBA/2JSf males have been tested and found to be Slp-negative. A number of pregnant females from positive strains were tested and also found to be negative.

On Sephadex G-200 gel, filtration peak concentration of Slp antigen is detected in those fractions with a molecular weight range of approximately $125,000-155,000$, based upon comparison with hemoglobin, albumin, and blue dextran 2000 (Pharmacia). Although these fractions are also positive for the Ss protein, the peak of Ss activity occurs in somewhat earlier fractions. The Slp antigen is heat-stable only to $50-52 \mathrm{C}$ for $20 \mathrm{~min}$, and substantial reduction of antigenic activity occurs after 3 days' storage at $4 \mathrm{C}$. This stability is significantly less than the value for the Ss protein, which was heat-stable to $70 \mathrm{C}$ for $20 \mathrm{~min}$. Both antigens, however, have identical $p \mathrm{H}$ stability ranges of 3.2-11.0.

Although no precise determinations have been done, it appears that Slp-a strains differ somewhat in quantitative levels of the Slp antigen, as determined by both the intensity and the position of precipitin bands on immunodiffusion. All the positive strains, however, give moderate to strong reactions, with the exception of strain BDP/J. Eight $\mathrm{BDP} / \mathrm{J}$ males that have been repeatedly typed give the following reactions: two moderately positive, four very weakly positive, and two negative.

\section{DISCUSSION}

The results demonstrate the existence of a serum protein variant in the house mouse detected by a specific alloantiserum on agar immunodiffusion. The genetic data are consistent with the hypothesis of control by a single autosomal dominant gene. Two of the characteristics of this variant system are particularly interesting. The antigen is 
normally expressed only in males of the proper genotype; hence the name of this variant, sex-limited protein (Slp). Secondly, our results show that the genetic determinant for Slp is linked to and maps within the $H-2$ region of linkage group IX. Since testing the original seven recombinants reported in this paper, we have recently analyzed seven additional informative crossovers and find them to be consistent with the positioning of the $S l p$ determinant within the $H$-2 region.

One of the most important questions to be answered from the results is: Does the Slp trait represent the structural variation in the Ss protein which was originally sought? Both agar immunodiffusion and absorption studies show significant cross-reactivity between Ss protein and the Slp antigen, and it seems rather clearly established that all molecules which carry SIp antigen sites also carry the antigenic determinants for Ss. Whether there are Ss molecules without Slp sites is not yet clear. In any case, the immunological evidence would seem to indicate that the Slp antigenic site is on the quantitatively variant Ss protein. The similar migration of Ss and Slp antigens on agar immunoelectrophoresis and their identical genetic map position within the $H$-2 region are a lso consistent with this interpretation.

Since the Slp variant is defined by an alloantiserum, it is reasonable to assume that the distinction between Slp-a and Slp-o is based on a structural difference. The genetic data map this structural difference in the $S$ s subdivision within the $H$-2 region. If the Slp antigenic site is on the Ss protein, the Slp alloantiserum must be defining structural differences in the Ss protein. One might then postulate that the $S s$ locus is probably the structural locus for this protein, rather than a regulatory locus. However, such a conclusion is complicated by the fact that the Slp trait is sex-limited, with the structural variation expressed only in males. This complication could be accounted for if some basic structural variation exists in the Ss protein which is exposed, modified, or activated only in the male environment. While models in which the $S s$ determinant functions as a regulatory locus cannot yet be ruled out, the structural locus model appears far less complex at present. The discovery of an Slp specificity antithetical, or allelic, to Slp-a would strengthen the argument that $S_{S}$ is a structural locus, since it is highly unlikely that different alleles at a regulatory locus could each control or turn on a series of different antigenic specificities determined by another locus. A regulator gene would be expected to affect a structural gene in a quantitative manner, not in a qualitative manner. Further immunizations with Slp-o male serum are being carried out in an attempt to define additional Slp specificities.

The Slp variant is a useful marker in the genetic analysis of both the $S s$ determinant and the complex $H-2$ region. Slp types subdivide the large number of Ss-H inbred strains into two groups: Ss-H Slp-a and Ss-H Slp-o. This distinction then becomes useful in the analysis of a large number of intra- $H-2$ recombinants which do not differ with respect to Ss. Thus Slp provides an intra- $H-2$ marker useful in the analysis and positioning of $\mathrm{H}-2$ specificities in recombinants originating from heterozygote combinations such as $H-2^{a} / H-2^{b}$ and $H-2^{d} / H-2^{b}$, e.g., those which have been reported by Gorer and Mikulska (1959) and by Stimpfling and Richardson (1965). Assuming that the Slp antigenic sites do in fact represent structural differences in the Ss protein, the location of the $S l p$ determinant within the $H-2$ region confirms still more strongly the previously indicated map position of the $S s$ determinant (Shreffler, 1967). 
Snell et al. (1964) and Shreffler (1965) have discussed the influence of the location of the $S s$ locus on the interpretation of the genetic organization of the $\mathrm{H}$-2 region. In these discussions, it was suggested that if the $S s$ locus maps within the $H-2$ region, and if it determines a protein functionally or antigenically unrelated to $H-2$, then one is forced to view the $H-2$ region as being made up of more than one functional locus, i.e., two histocompatibility loci separated by a locus for the Ss protein. The work that we have presented on the SIp variant bears on this suggestion of multiple loci in two ways. First, the Slp variant adds support for location of the Ss variant with the $H-2$ region. Secondly, our evidence suggests that the $S$ s locus may be the structural locus for the Ss protein. This new information, plus the fact that Ss and Slp still have not been functionally related to $\mathrm{H}-2$, tend to support the idea of a multicistronic $H-2$ region. A final conclusion must await further analysis of the nature of the Slp structural difference.

Potentially one of the most useful aspects of the Slp variant is the sex-limitation. Recent results from castration and hormone treatment of both male and female mice indicate that the development and maintenance of the Slp-antigen is strongly dependent on the male hormone environment (Passmore, 1969). Therefore, this sex-limited system could prove extremely valuable in the study of hormonal regulation of gene expression.

\section{REFERENCES}

Gorer, P. A., and Mikulska, Z. B. (1959). Some further data on the H-2 system of antigens. Proc. Roy. Soc. London B151: 57.

Hirschfeld, J. (1959). Invididual precipitation patterns of normal rabbit sera. Acta Pathol. Microbiol. Scand. 46: 229.

Passmore, H. C. (1969). The influence of male hormone on a sex-limited serum protein variant in the house mouse. Genetics 61: s45 (abst.).

Passmore, H. C., and Shreffler, D. C. (1968). A sex-limited serum protein variant associated with the $H-2$ region of the mouse. Genetics 60: 210 (abst.).

Preer, J. R. (1956). A quantitative study of a technique of double diffusion in agar. J. Immunol. 77: 52.

Ridgway, G. J., Klontz, G. W., and Matsumoto, C. (1962). Intraspecific differences in the serum antigens of red salmon demonstrated by immunochemical methods. Intern. North Pacific Fisheries Comm. Bull. 8: 1.

Shreffler, D. C. (1964). A serologically detected variant in mouse serum: Further evidence for genetic control by the histocompatibility-2 locus. Genetics $49: 973$.

Shreffer, D. C. (1965). The Ss system of the mouse-A quantitative serum protein difference genetically controlled by the $H-2$ region. In Palm, J. (ed.), Isoantigens and Cell Interactions, Wistar Institute Press, Philadelphia, p. 11.

Shreffler, D. C. (1967). Genetic control of cellular antigens. In Crow, J. F., and Neel, J.V. (eds.), Proceedings of the Third International Congress on Human Genetics, Johns Hopkins Press, Baltimore, p. 217.

Shreffler, D. C., and Owen, R. D. (1963). A serologically detected variant in mouse serum: Inheritance and association with the Histocompatibility-2 locus. Genetics 48: 9 .

Shreffler, D. C., Amos, D. B., and Mark, R. (1966). Serological analysis of a recombination in the $\mathrm{H}-2$ region of the mouse. Transplantation 4: 300 .

Snell, G. D., Hoecker, G., Amos, D. B., and Stimpfling, J. H. (1964). A revised nomenclature for the histocompatibility-2 locus of the mouse. Transplantation $2: 777$.

Stimpfling, J. H. (1961). The use of PVP as a developing agent in mouse hemagglutination tests. Transplant. Bull. 27: 109.

Stimpfling, J. H., and Richardson, A. (1965). Recombination within the histocompatibility-2 locus of the mouse. Genetics 51: 831 . 